\title{
State of the Art and Future Challenges in Multiple Sclerosis Research and Medical Management: An Insight into the 5th International Porto Congress of Multiple Sclerosis
}

\author{
María José Sá · Ricardo Soares dos Reis · Ayse Altintas • Elisabeth Gulowsen Celius • \\ Claudia Chien · Giancarlo Comi · Francesc Graus · Jan Hillert · Jeremy Hobart · Gulfaraz Khan • \\ Najib Kissani · Dawn Langdon · Maria Isabel Leite · Darin T. Okuda · Jacqueline Palace • \\ Regina María Papais-Alvarenga · Inês Mendes-Pinto · Fu-Dong Shi
}

Received: May 11, 2020 / Published online: July 14, 2020

(C) The Author(s) 2020

\section{ABSTRACT}

The 5th International Porto Congress of Multiple Sclerosis took place between the 14th and 16th of February 2019 in Porto, Portugal. Its intensive programme covered a wide-range of

Digital Features To view digital features for this article go to https://doi.org/10.6084/m9.figshare.12594623.

M. J. Sá $(\varangle)$ · R. Soares dos Reis $(\varangle)$

Department of Neurology, Centro Hospitalar Universitário de São João, Alameda Prof. Hernáni Monteiro, Porto, Portugal

e-mail: mjsa@med.up.ptR. Soares dos Reis

e-mail: r.soaresdosreis@gmail.com

M. J. Sá

Faculty of Health Sciences, University Fernando Pessoa, Rua Carlos da Maia, Porto, Portugal

\section{R. Soares dos Reis}

Department of Clinical Neurosciences and Mental

Health, Faculty of Medicine, University of Porto,

Porto, Portugal

A. Altintas

Department of Neurology, School of Medicine, Koç University, Istanbul, Turkey

\section{E. G. Celius}

Department of Neurology, Oslo University Hospital, Ullevål, Oslo, Norway

E. G. Celius

Institute of Clinical Medicine, University of Oslo, Oslo, Norway themes-including many of the hot topics, challenges, pitfalls and yet unmet needs in the field of multiple sclerosis (MS) - led by a number of well-acknowledged world experts. This meeting review summarizes the talks that took place during the congress, which focussed on issues in MS as diverse as the development and challenges of progressive MS, epidemiology, differential diagnosis, medical management, molecular research and imaging tools.

\section{Chien}

NeuroCure Clinical Research Center, NeuroCure Cluster of Excellence, Charité-Universitätsmedizin Berlin, Berlin, Germany

\section{G. Comi}

Department of Neurology, University Vita-Salute San Raffaele, Milan, Italy

\section{F. Graus}

Department of Neurology, August Pi i Sunyer Biomedical Research Institute (IDIBAPS) Hospital Clínic, Barcelona, Spain

\section{J. Hillert}

Department of Clinical Neuroscience, Karolinska Institutet, Stockholm, Sweden

\section{J. Hobart}

Department of Neurology, University Hospitals

Plymouth, Plymouth, UK

\section{J. Hobart}

Peninsula Schools of Medicine and Dentistry, University of Plymouth, Plymouth, UK 
Keywords: Congress review; Demyelinating diseases; Multiple sclerosis; Neurological diseases

\section{Key Summary Points}

Multiple sclerosis (MS) is an immunedriven neurological disease with a conspicuously heterogeneous distribution that affects approximately 2.3 million people worldwide.

The 5th International Porto Congress of Multiple Sclerosis took place on February 2019 in the city of Porto, Portugal, and brought together a number of worldknown experts in the field who shared their latest discoveries and discussed targets in MS healthcare that have yet to be met.

This review summarizes the main talks given during the congress, including the state-of-the-art description, groundbreaking projects and promising results.

G. Khan

Department of Microbiology and Immunology, College of Medicine and Health Sciences, United Arab Emirates University, Al Ain, United Arab Emirates

N. Kissani

Neurology Department, Marrakech University

Hospital Mohammed VI, Marrakech, Morocco

N. Kissani

Neuroscience Research Laboratory, Marrakesh

Medical School, Cadi Ayyad University, Marrakech,

Morocco

D. Langdon

Department of Psychology, Royal Holloway,

University of London, London, UK

M. I. Leite · J. Palace

Nuffield Department of Clinical Neurosciences,

University of Oxford, Oxford, UK
Discussed topics are as diverse as the epidemiology of MS in different continents, the development of and pitfalls in progressive MS, differential diagnosis and related diseases, medical management, cognitive impairment and its consequences, pregnancy and family planning and advances in molecular research and imaging techniques.

\section{INTRODUCTION}

Multiple sclerosis (MS) is an immune-driven neurological disease that has a profound impact on patients' quality of life (QOL). MS affects approximately 2.3 million people worldwide, and its prevalence is remarkably heterogeneous, varying from 50 to 300 patients per 100000 inhabitants [1]. Most patients are diagnosed during early adult life, and women have a markedly higher incidence. Overall, there is evidence for MS onset being triggered by environmental factors in genetically predisposed individuals, such as low vitamin D levels, cigarette smoking and obesity in early life [1]. Approximately $85-95 \%$ of the patients present a relapsing-remitting course (RRMS),

D. T. Okuda

Department of Neurology and Neurotherapeutics, UT Southwestern Medical Center, Dallas, TX, USA

R. M. Papais-Alvarenga

Universidade Federal do Estado do Rio de Janeiro (UNIRIO), Rio de Janeiro, Brazil

I. Mendes-Pinto International Iberian Nanotechnology Laboratory, Braga, Portugal

F.-D. Shi

Beijing Tiantan Hospital, Capital Medical University, Beijing 100070, China 
characterized by relapsing phases intertwined with periods of neurological stability $[2,3]$. However, MS can also assume a progressive course, characterized by a steadily increasing neurological decline, either from the onset (primary progressive MS [PPMS]), or within 15-25 years of RRMS diagnosis (secondary progressive MS [SPMS]) $[2,3]$. The MS diagnosis remains challenging and relies on the integration of clinical, laboratory and imaging findings, with the McDonald criteria being used by most neurologists [2].

The 5th International Porto Congress of Multiple Sclerosis, held in Porto (Portugal) in February 2019, had an ambitious programme and covered many of the hot topics, challenges and unmet needs in the MS field. In front of an audience composed of researchers, clinicians and patients, several internationally acknowledged specialists presented state-of-the-art, ground-breaking projects and promising results. The aim of this article is to provide an overview of the main issues discussed in the meeting and is based on previously conducted studies by the authors.

\section{PROGRESSIVE MS: DEVELOPMENTS AND PITFALLS}

Giancarlo Comi (San Raffaele Hospital, Italy) gave the meeting's magistral conference, in which he discussed the main advances in progressive MS and the as yet unmet needs of patients suffering from this clinical form of MS. Immunopathological studies have revealed a large overlap of lesion load between relapsing and progressive MS courses, with some qualitative differences in the distribution of lesion subtypes [4-6]. In progressive MS, most of the lesions are inactive, with only a small proportion of active lesions in the late phase and a predominance of chronically active, slowly expanding lesions, i.e. the smoldering lesions characterized by a hypocellular demyelinated core with a variable axonal degeneration and hypercellular edge of activated microglia and reactive astrocytes $[4,5]$. Subpial cortical lesions, in contrast, are abundant in the progressive forms of the disease (either PPMS or
SPMS), but are rarely seen among early RRMS $[3-5,7]$.

Moving from the disease's pathology to its clinical phenotype, Comi underscored the recent changes made to the classification of progressive MS: whereas the focus was traditionally placed on the presentation of the progressive phenotype (primary vs. secondary), the new classification now focusses on disease activity and disability evolution [8]. In fact, and while the terms PPMS and SPMS are still used, two new concepts were introduced into this classification: disease activity (based on the presence of relapses and/or active lesions, such as new T2 magnetic resonance imaging (MRI) lesions and/or gadolinium-enhancing lesions) and disability evolution (i.e. a gradual worsening of disability in a relapse-independent fashion or stable disability) [8]. For Comi, this classification provides a more accurate description of the true nature of progressive forms of MS because the presence/absence of disease activity has clear treatment implications and there is a remarkable variation in the speed of disability progression among different patients. The identification of the key factors that drive this variability will be a critical step for a better understanding of the disease and, ultimately, for improving patients' care.

Another aspect addressed by Comi was the need for better diagnostic and monitoring tools. In this context, he highlighted the recent advances in MRI technology, as well as the importance of measuring brain and spinal cord atrophy and of complementing the traditional assessments with functional measures, such as evoked potentials and optical coherence tomography (OCT) (some of these aspects were discussed in more detail by other speakers and are described in following sections of this article). He also underscored the role of body fluid biomarkers, highlighting the particularly attractive findings made in the context of neurofilaments [9].

Finally, Comi mentioned the lack of therapeutic alternatives for progressive MS: in fact, despite the notable growth of the RRMS therapeutic armamentarium, few disease-modifying drugs (DMDs) have shown positive results in patients with progressive MS. Those which 
did-siponimod and ocrelizumab-mostly target inflammatory elements of the disease cascade $[10,11]$. Nonetheless, Comi considered that an improvement of care in progressive MS will require looking beyond the inflammatory pathway, extending research towards neuroprotective and repair-promoting strategies.

\section{EPIDEMIOLOGY AND RECENT ADVANCES}

The geographical distribution of MS is one of the most striking aspects of this disease's epidemiology: with a number of exceptions, its prevalence seems to increase with increasing distance from the equator [1]. However, there are also some remarkable geographical disparities in the availability of neurologists and diagnostic tools, as well as in MS severity and progression. To achieve an integrated insight into these issues, specialists from all over the world were invited to discuss the main aspects of MS epidemiology in their respective regions and the main concerns of neurologists, as well as some of the latest developments in research.

Ayşe Altintaş (Koç University, Turkey) gave a general overview of MS prevalence and state of care in Turkey. Interestingly, although Turkey has long been considered to be a low-incidence country-the 2013 MS International Foundation report estimates its prevalence to be in the range 20.01-60 cases per 100,000 inhabitants [12]—recently published articles have suggested otherwise. For example, Börü et al. have assessed the prevalence of MS among the inhabitants of three Turkish cities, two of which are located in the Black Sea region (Artvin and Ordu) and one located in the Mediterranean region (Gazipaşa) [13]. These cities, which were chosen due to their location and low immigration rate, were reported to have an MS prevalence of 18.6, 55.5 and 52.0 cases per 100,000 inhabitants, respectively [13]. Another study, which focussed on the prevalence of MS in the Middle Black Sea Region of Turkey, reported 43.2 cases per 100,000 inhabitants [14]. Other studies have described an MS prevalence of 41.1 cases per 100,000 inhabitants of Geyve (a rural area in the Black Sea Region) and of 101.4 cases per 100,000 inhabitants of the district of Maltepe (Istanbul) $[15,16]$. Consequently, it is now believed that the true prevalence of MS in Turkey should be within these latter limits. On the other hand, with respect to specialist care and resources, Turkey seems to be in a fairly good position. According to Altintaş, there are over 2000 neurologists in the country, of whom 118 are currently dedicated to studying and managing MS and other demyelinating diseases. The McDonald criteria are usually applied for diagnosis, and the number of available MRI scanners exceeds 800. Most therapies and DMDs are available and easily accessible to patients (through the public health system and/or private health insurances), and treatment strategies follow the international guidelines with minor local adjustments.

Najib Kissani (University Hospital Mohamed VI, Morocco) addressed the prevalence and the progression of MS in Africa. African countries can be divided into three different zones according to their MS prevalence: the north, comprising countries such as Morocco, Tunisia, Egypt and Algeria, which is described as a mild to high prevalence area (30-80 cases per 100,000 inhabitants); the south, namely South Africa, which is a mild prevalence area (10-30 cases per 100,000 inhabitants); and the rest of sub-Saharan Africa, which is a very low prevalence area $(<5$ cases per 100,000 inhabitnts). This scenario, however, is likely driven by a high rate of underdiagnosis, stemming from the worrisome lack of resources and specialists in many sub-Saharan countries. Interestingly, and despite the low prevalence, MS cases in Africa seem to be characterized by a higher severity and a faster progression rate (when compared to the rest of the world). Indeed, in one Moroccan cohort including 380 patients with MS (372 of whom were Caucasian), the time to progression to an Expanded Disability Status Score (EDSS) of 6 was only 10 years. Importantly, this higher severity seems to be independent of the delay in diagnosis (which was 2.5 years in the Moroccan series). Other studies have reported similar trends in severity $[17,18]$, and Sidhom et al. highlighted that the higher severity in North Africans is independent of patient location (within or outside Africa) [19], which suggests a 
genetically driven explanation. Kissani also shared the results of a questionnaire he sent to his African colleagues-in an attempt to understand the true prevalence of MS in African countries-highlighting not only the low number of MS cases reported, but also the comparably high incidence of neuromyelitis optica (NMO) and the problematic lack of resources and therapies (in most cases, the only treatments available were corticosteroids). Kissani finished his presentation by underpinning the necessity of more studies (supported by robust collaborations) to understand-and tackle-the MS low prevalence/high severity dichotomy in Africa.

Fu-Dong Shi (Tianjin Medical University General Hospital, China) discussed the MS landscape in China, focussing on the latest advances in the diagnosis and treatment of both MS and NMO Spectrum Disorder (NMOSD). The prevalence of MS in China is unknown; however, when data from Hong Kong and the neighbouring countries of Japan and Korea are taken into consideration, MS prevalence in China is estimated to be between 5 and 10 cases per 100,000 inhabitants, while the ratio of MS:NMOSD seems to be $2: 1$. Regarding treatments, while not all currently used drugs are available in China, the scenario is quickly changing, and drugs such as fingolimod, dimethyl fumarate and dalfampridine are in the pipeline for a quick approval. According to Shi, one of the greatest diagnostic dilemmas concerning MS in China is the prediction of conversion after a clinical isolated syndrome (CIS) in the presence of changes in white matter. In this respect, Shi presented BioMind, a diagnostic support system that uses deep learning technology to analyse MRI and computed tomography images, increasing the accuracy of diagnosis by $20 \%$ (when compared to the human eye). Other ongoing projects mentioned by Shi included the utilization of OCT to discern between MS and NMOSD [20]; the identification of immune markers able to predict CIS conversion; the responsiveness to a reduced dose of rituximab in NMO patients [21]; the utilization of bortezomib in NMOSD patients [22]; and the efficacy and safety of tocilizumab in NMOSD patients.
Regina Papais-Alvarenga (Federal University of the State of Rio de Janeiro, Brazil) discussed the prevalence and risk factors for MS in Latin America (LA), a region characterized by an heterogeneous and genetically complex population. Although LA comprises 20 countries, most MS studies published to date have been conducted in only six of these-Brazil, Argentina, Mexico, Colombia, Chile and Cuba. Overall, LA seems to be an area of low to medium MS prevalence, with rates varying from 0.83 to 21.5 cases per 100,000 inhabitants [23]. More specifically, in Brazil, a systematic review by Pereira et al. reported MS prevalence rates varying between 1.36 (in the northeastern region) and 27.2 (in the southern region) per 100,000 inhabitants [24]. This distribution is likely driven by genetic factors, although environmental risk factors may also play a role in the dynamics of MS prevalence [25, 26]. Familial MS cases seem to be rare in the countries of LA, with values ranging from 3.3\% (in Mexico) to $10.5 \%$ (in Buenos Aires). However, the relative frequency of NMO in NMO + RRMS cases in LA is higher than that reported for Europe and Australia: in fact, a multicentre study involving 1917 patients revealed NMO relative frequencies ranging from $2.1 \%$ (in Argentina) to $43.3 \%$ (Venezuela) [27]. This variation was related to ethnicity, with higher frequencies found among non-white populations, a finding which confirms results from previous studies.

Jan Hillert (Karolinska Institutet, Sweden) presented the Swedish MS Registry and discussed the implications of registry data for research. The Swedish MS Registry was started on 2000 and became web-based in 2004: it currently includes data pertaining to 17,000 patients (of the 20,500 MS patients in Sweden) from all 64 neurology units that exist across the country [28]. At the start of a consultation, by opening a patient's registry, the physician has immediate access to a set of data providing valuable information, including a temporal line representing patient progression [according to the EDSS and MS Severity Score (MSSS)], current and past DMDs and other treatments, MRI results, MS attacks and functional tests, among other information [28]. Importantly, the longterm clinical data in the Swedish MS Registry 
can be used to improve our understanding of MS. In this context, Hillert provided several examples in which the Swedish MS Registry was used as the basis of pertinent investigations in the field. Among these was the identification of MS progression trends in Sweden (namely, a tendency towards a slower progression and a decreased risk of reaching EDSS 3, 4 and 6 [29]; a decrease in MS costs [30]; and a lower incidence in primary progressive MS [31]). Moreover, registry data have also been used to identify risk factors and predict secondary progressive MS [32] and to identify socioeconomic consequences of disease progression [33]. Finally, the Swedish MS Registry was useful to show that the risk of MS progression can be ameliorated by the utilization of DMDs [34], as well as by an early introduction of these therapies $[35,36]$, and that smoking cessation can slow down disease progression [37]. Hillert also mentioned that an unification of several national Swedish MS registries has recently taken place, allowing the integration of data and making available larger cohorts for investigational studies (three of which are currently ongoing) and for post-approval safety studies (also being launched).

\section{MS-RELATED DISEASES AND DIFFERENTIAL DIAGNOSIS}

Despite the remarkable advances achieved in the fields of imaging, pathology and immunology in recent years, MS diagnosis remains challenging [38]. One important-and many times puzzling - step is to differentiate MS from other neuroinflammatory disorders, namely those of a demyelinating nature. Two renowned neurologists-Francesc Graus and Jacqueline Palace-were invited to the 5th International Porto Congress of Multiple Sclerosis to discuss the diagnosis, outcomes and therapeutic options of two neuroinflammatory disorders other than MS.

Francesc Graus (University of Barcelona, Barcelona) discussed the physiopathology of autoimmune encephalitis, highlighting the need to loosen the boundaries between the fields of autoimmunity and neurodegeneration. Starting with a retrospective overview of the topic, Graus mentioned that the relationship between limbic encephalitis and cancer has been known for over 50 years, with Corsellis et al. first describing patients $(n=3)$ with this form of encephalitis and small-cell lung cancer in 1968 [39]. The subsequent identification of antibodies reacting with both intracellular brain and tumour antigens suggested that limbic encephalitis was actually immune mediated, although by then this immune attack was considered to be mainly driven by T-cell infiltrates [40]. Finally, the identification of different antibodies reacting against intracellular and neuronal surface antigens led to the current belief that these antibodies are, indeed, the main pathogenic agents, a finding which supports the development of different forms of encephalitis. Importantly, serological tests should not be mandatory when considering the diagnosis of autoimmune encephalitis and starting the treatment. An initial diagnosis of autoimmune encephalitis can be made on the basis of the patient's clinical symptoms and using conventional tests, as described in Graus et al. [41]. Still, the identification of which antibodies are present is important to confirm the diagnosis and determine patient prognosis and the likelihood of cancer development. AntiLGI1 is one of the most common antibodies related to encephalitis: patients with this form of the disease are mostly men (60-70\%) and between 50 and 70 years of age and, in most cases (87\%), have the limbic phenotype. Importantly, patients with anti-LGI1 encephalitis develop faciobrachial dystonic seizures before encephalitis itself and can therefore be misdiagnosed. Anti-NMDA receptor (NMDAR)-associated encephalitis, which mainly affects young women and children, is another important form of the disease. Interestingly, patients with this form of encephalitis typically present with psychiatric symptoms, with the neurological signs following shortly thereafter. It should also be taken into consideration that autoimmune encephalitis, and namely anti-NMDAR encephalitis, can be triggered by herpes simplex encephalitis [42]. The best therapy for these diseases is still under discussion: the development of clinical trials is hindered by the low number of cases and, 
therefore, all knowledge gathered to date is of a retrospective nature. Steroids are the most common first-line therapy for anti-LGI1 encephalitis (with rituximab as the most common second-line therapy), and most patients have positive outcomes. Still, around $25 \%$ of patients become fully dependent or acquire severe cognitive deficits [43]. The scenario is similar with the anti-NMDAR forms of encephalitis, with approximately $80 \%$ of patients showing a good outcome after immunotherapy or tumour removal [44]. Importantly, patients who switched therapy after an unsuccessful first-line treatment had better outcomes that those who did not switch, suggesting the importance of considering alternative treatments in difficult cases [44].

Jacqueline Palace (University of Oxford, UK) gave an overview of myelin oligodendrocyte glycoprotein (MOG) antibody disease, focussing on its distinctive features and diagnosis criteria. MOG is a structural glycoprotein found at the surface of myelin in the central nervous system (CNS). Anti-MOG disease, which is distinct from MS and mutually exclusive from antiaquaporin 4 (AQP4) disease, can be classified into multiple clinical phenotypes, including acute disseminated encephalomyelitis, transverse myelitis, optical neuritis $(\mathrm{ON})$ and cortical disease. Two large cohorts of anti-MOG patients have been recently characterized and shown to have a remarkably similar distribution of features, namely the female:male ratio (57 and $49 \%$ females), the incidence of relapsing disease (46 and $42 \%$ ), the percentage of Caucasian patients (85.8 and $92.9 \%)$ and the predominance of ON (unilateral or bilateral) as the main disease manifestation $[45,46]$. The results of these studies are utterly important to our understanding of the epidemiology of antiMOG disease, and are referred to several times by Palace, as seen below; however, it should be kept in mind that both studies were carried out in "Caucasian" countries and, therefore, the possibility of having different trends in countries where the percentage of Caucasian people is different from those noted above cannot be excluded. Regarding diagnosis, Palace highlighted the Matthews criteria of "at least one lesion adjacent to the body of the lateral ventricle and in the inferior temporal lobe; or the presence of a subcortical U-fiber lesion; or a Dawson's finger-type lesion" for distinguishing patients with MS from those with NMOSD with a sensitivity of $92 \%$, specificity of $96 \%, 98 \%$ positive predictive value and $86 \%$ negative predictive value [47]. These imaging findings may, however, be similar in anti-MOG disease. With respect to the course of disease, both cohorts mentioned above were again very similar, with 41 and $43 \%$ of patients relapsing within 24 months $[45,46]$. Interestingly, most of these patients relapsed in a rather early phase of the disease. Additionally, no relapses were reported for those patients who became antiMOG negative (28\% of the initial patients, $88 \%$ of whom stayed negative until the end of the follow-up), and therapy for periods longer than 3 months seemed to reduce the risk of relapse [45]. Disability seemed to affect patients with anti-AQP4 disease more severely than those with anti-MOG disease, irrespective of the severity of the relapses $[45,46]$. Still, a considerable number of anti-MOG patients developed sphincter-related disability, namely permanent bladder dysfunction (28\%), bowel dysfunction (20\%) and erectile dysfunction (21\% of male patients) [45]. The best treatment for patients with anti-MOG disease is still under discussion: a possible algorithm, recently published, includes testing for anti-MOG antibodies after an initial 6-month course of corticosteroids and considers extra courses for patients who test positive; patients with late relapses are candidates for long-term immunosuppression [48]. The best immunosuppressive drug for these patients, however, is yet to be identified: in fact, two recent studies that examined the relapse rate of patients with anti-MOG disease on different treatments yielded distinct values for similar therapies $[49,50]$.

\section{MEDICAL MANAGEMENT AND PATIENTS' DAILY LIFE ACTIVITIES}

The impact of MS and other demyelinating diseases, such as NMOSD, on patients' QOL is both devastating and complex. The importance 
of setting thresholds to define an early and effective medical intervention was the theme of one of the talks discussing this topic; others were focused on the cognitive impairment associated to MS, and on family planning and pregnancy in patients with MS and NMOSD.

Jeremy Hobart (University of Plymouth, UK) presented the MS Brain Health Initiative (https://www.msbrainhealth.org/), which is based on the importance of a time-efficient approach to the different stages of the disease, with the ultimate aim to improve MS care at an international level. Importantly, whereas the dysfunction generated by other diseases can be ameliorated or cured with organ transplantation, MS patients have no such option: the accumulated damage to the CNS is mostly irreversible. As such, a time-wise care strategy able to prevent the accumulation of such damage would represent an immense benefit to MS patients. In this context, the "Brain HealthTime Matters in Multiple Sclerosis" report details a series of explicit recommendations pertaining to the urgency of care at every stage of MS [51]. Following the publication of this report, and in an attempt to turn these recommendations into tools that can be used in daily clinical practice, a group of neurologists carried out a Delphi methodology-based study to define the optimal time frames that should be met in different stages of the disease [52]. These time frames were divided into 'core', 'achievable' and 'aspirational', reflecting minimum, good and high standards of MS care, respectively. For example, the time frame within which a diagnostic workup should be completed after referral to a neurologist is 2 months (core), 4 weeks (achievable) or 7 days (aspirational) [52]. Clinical teams are thus provided with international standards against which they can compare their own performance, thereby enabling them to identify their own strengths and weaknesses, and to focus on areas that need improvement. To further facilitate this, quality improvement tools-based both on physicians' and patients' reports-are being developed and tested (pilot phase).

Dawn Langdon (Royal Holloway, University of London, UK) discussed the importance of cognitive impairment in MS and its impact on patients' QOL. Cognitive deficits are common among MS patients and are known to interfere in different life domains $[53,54]$, with perhaps one of the most important being employment status $[55,56]$. Moreover, cognitive impairment also affects the patient-doctor relationship and the shared process of therapeutic decisionmaking, as recent therapies and DMDs often carry with them an intricate network of risks and benefits that is notoriously hard to perceive. Interestingly, cognition is an important predictor of neurological outcomes and morbidity/psychosocial risks among MS patients. In terms of neurological outcomes, cognitive impairment is known to be related with the risk of conversion to MS after CIS [57], while cognitive deficits assessed immediately after diagnosis can predict the degree of disability and disease progression several years later [58, 59]. Regarding morbidity risks, cognition is known to be related with medication adherence [60], decision-making ability and speed [61, 62], symptom management [63], fear of falling and actual falls [64-71] and driving safety [72-75]. Finally, with respect to psychosocial risks, cognition has been reported as being linked to employment and working status [76], psychiatric disturbances and associated co-morbidities $[77,78]$, financial abilities $[79,80]$, participation in domestic, leisure and outdoor activities [81-85], social cognition and emotional awareness [86, 87] and caregivers' QOL [88, 89]. Given all of the above, the importance of neuropsychological assessment in MS patients is indisputable. However, Langdon highlighted that cognition self-report is often unreliable, being confounded by a number of different factors (such as depression, anxiety, fatigue, conscientiousness, perceived stress and self-efficacy) [90-93]. In this context, a committee of experts has analysed and recommended a set of toolsnamed the Brief International Cognitive Assessment for Multiple Sclerosis (BICAMS) that aims to allow a fast cognitive assessment of MS patients in small centres (which may lack neuropsychological experts) at an international level [94].

Maria Isabel Leite (University of Oxford, UK) discussed the implications of pregnancy in patients with NMOSD, focussing particularly on 
those with anti-AQP4 antibody disease. Pregnancy is a matter that should be taken into account because most NMOSD patients are female and of child-bearing age: in fact, according to Kim et al., $84-90 \%$ of NMOSD patients are female, and the average age at onset varies from 33 to 43 (being slightly lower for Asian and African-American/African-European patients) [95]. Leite divided her presentation into two main topics, with the first focussing on the effects of pregnancy on NMOSD disease activity, and the second focussing on the influence of NMOSD on pregnancy outcomes and foetal development. With respect to the former, several retrospective studies have shown that the relapse rate may increase slightly during the third trimester of pregnancy (although in a non-significant manner) and is generally higher in the 3- to 6-month postpartum period [96-98]. Moreover, Simizu et al. reported that suboptimal immunosuppression seems to increase the risk of pregnancy-related relapses [99]. Regarding the impact of NMOSD on pregnancy outcomes, the studies available to date suggest an increased risk of miscarriage that seems to be independent of maternal age and miscarriage history (at least for pregnancies initiated after or up to 3 years before NMOSD onset) [100]. Additionally, patients with NMOSD have also an increased risk of preeclampsia, which is apparently independent of NMOSD onset but instead related with the presence of other autoimmune disorders [100]. On the other hand, and with the exception of a few reports on pre-term births without major complications, there are very few reports of complications in children born from NMOSDafflicted mothers. Leite also highlighted that, although there are no studies on the safety of drugs used during pregnancy in NMOSD patients, one can extrapolate from what is known in other diseases that azathioprine, cyclosporine, tacrolimus, prednisolone, intravenous immunoglobulin and plasma exchange are safe therapeutic options. Conversely, methotrexate, mycophenolate and rituximab should be used with extreme caution. Overall, in Leite's opinion, NMOSD should not be considered to be a contraindication for pregnancy, but rather patients should be thoroughly informed and closely monitored. Moreover, the choice of an adequate and effective treatment is a crucial step towards a positive outcome.

Elisabeth G. Celius (Oslo University Hospital, Norway) also discussed pregnancy and family planning, but with a focus on MS patients instead of patients with NMOSD, highlighting the increasing rate of pregnancy among MS patients in recent years [101]. Interestingly, MS does not seem to impact fertility, although it might be associated with sexual dysfunction. However, pregnancy itself causes a number of major immune changes, one of which is an increased immune tolerance. The clinical implications of this increased immune tolerance on the disease course were described in 1998 by Confavreux et al. [102] and confirmed 20 years later by Bsteh et al. [103]. As in NMOSD, it would appear that the rate of MS relapses decreases during pregnancy and increases in the post-partum period [102, 103]. That the same pattern was observed in cohorts separated by 20 years shows that the availability of modern treatments has had little impact on these pregnancy-related variation in relapse rate. As shown in the MSBase registry, the number of pregnancies initiated while on DMDs has increased over the last 12 years. The median time of DMD exposure is 30 days, suggesting that most women interrupt treatment when pregnancy is confirmed [104]. Interrupting treatment because of a planned or confirmed pregnancy carries an increased risk of rebound of disease activity, which is particularly relevant when therapy with fingolimod and natalizumab is interupted. In addition, some of the more commonly prescribed hormonal treatments meant to increase fertility in women who are trying to conceive might trigger disease activity. In contrast, glatiramer acetate may now be continued until pregnancy is established, and interferons also seem to be safe. Interferons and glatiramer acetate may be appropriate choices for women with mild to moderately active disease, whereas immune reconstitution therapy, using alemtuzumab or cladribine, should be considered for women with high disease activity before conception. Regarding alemtuzumab, a preliminary study reported by Celius et al. at the 34th Congress of 
the European Committee for Treatment and Research in Multiple Sclerosis (ECTRIMS 2018) has shown some promising results, particularly in terms of the absence of disease activity during pregnancy and post-partum in women with pre-treatment high disease activity [105]. Exclusive breastfeeding might offer some protection against MS relapses, although the reports published to date on this subject are conflicting [106, 107]. While none of the drugs are approved for use during breastfeeding, interferons, glatiramer acetate and alemtuzumab seem to be safe. Overall, future pregnancies should be taken into consideration when initiating therapy in women of childbearing age, and women should be informed of the possible risks related to a pregnancy that are associated with each of the different therapies available and the need for contraception. After giving birth, breastfeeding should be encouraged, and an MRI should be performed 4-6 weeks post-partum to assess disease activity. In the absence of disease activity, patients may consider continuing breastfeeding, but this decision should be re-evaluated after 3-4 months. Conversely, the detection of disease activity requires treatment re-initiation and usually the interruption of breastfeeding.

\section{BASIC AND APPLIED MOLECULAR RESEARCH}

Molecular research is a key field of MS investigation. As it would be impossible to discuss the multitude of interesting projects currently exploring MS-related molecular issues, two aspects were chosen to be presented at the 5th International Congress: the role of Epstein-Barr virus (EBV) infection in MS development, and the importance of identifying biomarkers and their potential in MS diagnosis and monitoring.

Gulfaraz Khan (United Arab Emirates University, UAE) dedicated his talk to the discussion of the role of EBV infection in MS immunopathology. EBV is an ubiquitous double-stranded DNA virus known to have tumourigenic properties. Its detection has been improved by a very specific and sensitive in situ hybridization technique developed by Khan and colleagues, which is based on the recognition of two small RNAs-EBER1 and EBER2 (EBV-encoded RNA 1 and 2) - that are expressed in all forms of infection known to date [108-110]. The association between EBV infection and MS has been studied for a long time, and numerous studies, such as those of Cepok et al. [111], Haahr et al. [112] and Ponsonby et al. [113], have provided indirect evidence suggesting the existence of a relationship. In fact, individuals with EBV immunoglobulins are at an increased risk of developing MS, and virtually all (99.5\%) patients with MS are EBV seropositive. Moreover, the levels of anti-EBV antibodies and specific $\mathrm{T}$ cells are higher in MS patients when compared to controls both before and after disease onset. The first direct evidence of the EBV-MS link came from the study of Serafini et al., who detected EBV infection in brain-infiltrating B cells and plasma cells in 21 of 22 patients with MS [114]. Interestingly, at least three studies published afterwards found no evidence of such a link [115-117], which has been suggested to be a consequence of technical issues and different sampling procedures [118]. Khan's group has recently examined 1055 samples extracted from MS and non-MS patients and shown that EBV is present in 91 of 101 (90\%) MS patients, but in only five of 21 (24\%) patients with other neurological conditions [119]. Moreover, none of the samples were positive for other common herpesviruses [HSV1 (Herpes simplex virus 1), CMV [Cytomegalovirus], HHV-6 [Human Herpesvirus 6]) [119]. Interestingly, the virus was transcriptionally active in only a few of the cells, being latent in the majority of them, which may be a mechanism by which it escapes immune surveillance $[119,120]$. Another interesting finding made by this group was that the virus was not only present in B cells, as expected, but also in astrocytes and microglia [119]. Khan and collaborators are currently working with an animal model of EBV infection [121], and the promising results from this study will certainly contribute to a better understanding of the impact of EBV in MS immunopathology.

Inês Mendes Pinto (International Iberian Nanotechnology Laboratory, Portugal) discussed the pertinence of using biosensors in 
neuroimmunological diseases and presented a device, designed and fabricated in her laboratory, that is able to detect different MS biomarkers. A biosensor is a device conceptually composed of a sensing module that is able to selectively recognize a given biomarker (i.e. anything from nucleic acids to entire cells) and a transducing module that translates the recognition reaction into a measurable signal. Ideally, a biosensor should be highly specific and sensitive, have minimal requirements in terms of sample volume and technical expertise and be efficient in terms of detection limits and time [122]. In the context of neuroimmunology, and particularly in the case of MS, there is a high demand for new diagnostic methods: the conventional platforms are usually ELISA (enzyme-linked immunosorbent assay)-based, restricted to central laboratories (as they require technical expertise), time-consuming (around $24 \mathrm{~h}$ from sampling to output reading) and costly. Other limitations include the requirement of large samples $(50 \mu \mathrm{L})$ and the impossibility to detect and monitor different biomarkers simultaneously (i.e., multiplex). In this context, Mendes Pinto's team has developed a portable biosensor that overcomes most of these limitations. This device is an electrochemical-based system able to detect different MS biomarkers using $1 \mu \mathrm{L}$ of body fluid (either cerebrospinal fluid, blood serum, tears or others) in less than $10 \mathrm{~min}$ and without requiring technical expertise. Specificity of the biomarkers is ensured by the chemical irreversible immobilization system used to cross-link the antibodies to the chip. Sensitivity depends on the biomarker(s) being detected, but is generally higher than that obtained with conventional tests (e.g. those for the detection of tumour necrosis factor $\alpha$ is around 40-fold more sensitive than the ELISA-based assays) [123]. Moreover, this biosensor can be integrated into a reader and connected to a computer or to a smartphone, from which the results can be directly read. All of the above characteristics make this chip a convenient and user-friendly bedside diagnosis and monitoring tool. In terms of cost-efficiency, this device can be produced in batches, which lowers its production cost. Overall, this biosensor-which is currently in its clinical validation stage-is a promising tool to diagnose and monitor MS patients in a rapid, cheap, time-efficient and minimally invasive fashion.

\section{ADVANCES IN MRI AND OTHER IMAGING TECHNIQUES}

Magnetic resonance imaging remains a pivotal tool in MS diagnosis and monitoring. Importantly, advances in this and other imaging techniques are improving the diagnostic ability and monitoring capacity in MS medical care. Issues discussed in this section included MRI itself, other complementary approaches and the value of applying artificial intelligence to threedimensional (3D) image analysis and automated segmentation.

Claudia Chien, who represented the Dr Friedemann Paul laboratory (Charité-Universitätsmedizin, Germany), presented the latest advances in imaging tools for application in neuroimmunological disorders, namely those related to MRI and OCT. Regarding MRI techniques, analysis of the central vein sign represents an important development: the presence of more than $50 \%$ perivenular lesions in the brain enables MS to be distinguished from other inflammatory vasculopathies with 100\% diagnostic accuracy [124]. Another major improvement to the field may be the utilization of cortical thickness atlases coupled with the mapping of myelin content $[125,126]$, as this approach may facilitate the analysis of the typical cortical and juxtacortical lesions in MS, which are often difficult to visualize using standard MRI. The analysis of functional visual networks by resting-state functional MRI has also brought some interesting results: the presence of $\mathrm{ON}$ was associated with a stronger connectivity in the visual network of patients with NMOSD or those who had suffered a CIS $[127,128]$. Finally, the improvement of automated techniques for the assessment of spinal cord atrophy, as well as the inclusion of this assessment into the routine monitoring of patients with MS and NMOSD, has now been pinpointed as an important research area for the future [129]. In this context, Gros et al. have 
recently published a method to segment spinal cord (and intramedullary) MS lesions on a variety of MRI sequences [130]. There have also been some advances in OCT recently: this highresolution imaging technique enables thickness analysis of individual retinal layers, two of which have proven to be particularly important in the context of MS-the retinal nerve fibre layer (RNFL) and the ganglion cell/inner plexiform layer (GCIPL). In fact, in one study, the most conspicuous differences between the eyes of MS and control patients were the peripapillary RNFL and the macular GCIPL [131]. Zimmermann et al. have also demonstrated that the thickness of the GCIPL may inform on future disease activity and risk assessment of conversion to MS in CIS patients [132]. As for NMOSD research, OCT-based studies have shown that GCIPL loss occurs independently of ON attacks in AQP4-positive patients [133] and that the presence of prior $\mathrm{ON}$ can be assessed with a relatively high sensitivity using thresholds of 6 and $3 \mu \mathrm{m}$ differences in RNFL and GCIPL thickness, respectively [134]. Overall, Chien considered that multi-modal imaging is the future, with the integration of different techniques allowing for a more accurate diagnosis and monitoring of neuroinflammatory diseases.

Darin Okuda (UT Southwestern Medical Center, USA) argued on the possibilities offered by artificial intelligence in the field of medical imaging, focusing on the potential of automated 3D analysis of white matter lesions in MS. MRI, by itself, has revolutionized the diagnosis and understanding of MS pathology. Moreover, it can inform on disease progression risks: the number of lesions after an isolated attack is known to be related with the risk of conversion to MS, whereas the temporal profile by which lesions accumulate over the initial years of the disease is helpful in predicting the risk of secondary progression later on. However, neurologists are often confronted with clinicoradiological paradoxes, i.e. patients whose MRI examination reveals devastating lesions but who are neurologically well, and patients who are in a poor neurological state but whose examination reveals nothing but small radiological changes. Indeed, it is now accepted that CNS lesions do not necessarily inform on the patients' clinical condition at the moment: these lesions are very dynamic and may not have clinical manifestations until several years later. Accordingly, Kantarci et al. have followed 453 subjects who suffered radiologically isolated syndromes; of these, 128 progressed to symptomatic MS, 15 of which evolved to PPMS [135]. According to Okuda, the value of 3D analysis of white matter lesions may reside in an improved ability to diagnose, distinguishing different types of lesions and providing patients with fine-tuned and personalized medical care. The automatic segmentation of the lesions, as opposed to the manual procedures, is often criticized; however, as these processes rely on the distinction of subtle shades, machine learning systems tend to perform better than the human eye. Whereas previous attempts at automatic segmentation focussed on lesion volume, the newest techniques can accurately determine shape and surface structure. These characteristics may inform on the origin of disease, provide insights into the extent of injury and even deliver some information on the capacity for self-remyelination. Additionally, 3D data may allow the identification of different pathologies within the brain of a single patient, resulting in more accurate and effective medical care.

\section{ACKNOWLEDGEMENTS}

Funding. The conference was supported by Almirall, Bayer, Biogen, Merck Serono, Novartis, Roche, Sanofi Genzyme and Teva, all of which had no role in its organization or scientific programme. Medical writing assistance and publication Rapid Service Fee were funded by ROCHE.

Medical Writing and/or Editorial Assistance. The authors are grateful to Dr. Catarina Santos and Springer Healthcare for help in the preparation of the manuscript.

Authorship. All named authors meet the International Committee of Medical Journal Editors (ICMJE) criteria for authorship for this 
article, take responsibility for the integrity of the work as a whole, and have given their approval for this version to be published.

Compliance with Ethics Guidelines. This article is based on previously conducted studies and does not contain any studies with human participants or animals performed by any of the authors.

Disclosures. Maria José Sá has received consulting fees from Bayer, Biogen, Merck Serono, Novartis, Roche, Sanofi Genzyme and Teva. Ricardo Soares dos Reis has received non-financial support for meeting attendance from Bayer, Biogen, Boehringer Ingelheim, Daiichi Sankyo, Eisai, GE Healthcare, Mylan, Novartis, Roche, Sanofi and Teva. Ayse Altintas has received speaker honoraria for non-promotional education events and travel grants from Merck, Teva and Novartis. Elisabeth Gulowsen Celius has received personal compensation for serving on scientific advisory boards for Almirall, Biogen, Merck, Novartis, Genzyme and Teva; and has received speaker honoraria from Biogen, Genzyme, Roche, Novartis, Merck and Teva. Her department has received unrestricted research grants from Biogen, Novartis and Genzyme. Giancarlo Comi reports financial activities outside the submitted work from Novartis, Teva Pharmaceutical Industries Ltd, Teva Italia Srl, Sanofi Genzyme, Genzyme Corporation, Genzyme Europe, Merck KGgA, Merck Serono SpA, Celgene Group, Biogen Idec, Biogen Italia Srl, F. Hoffman-La Roche, Roche SpA, Almirall SpA, Forward Pharma, Medday and Excemed. Francesc Graus reports royalties from Euroimmun for the use of IgLON5 as a diagnostic test and honoraria for assistant editor of MedLink Neurology. Jan Hillert reports, outside the submitted work, personal compensation for serving on scientific advisory boards for Sandoz, Biogen, Merck KGaA, Novartis, Sanofi-Genzyme and Celgene; has received speaker honoraria from Biogen, Sanofi-Genzyme, Novartis, Merck $\mathrm{KGaA}$ and Teva; and has received unrestricted research grants from Biogen, and commissioned research from Novartis, Sanofi-Genzyme, Merck and Roche. Jeremy Hobart has received consulting/advisor fees, honoraria and research support from Acorda, Biogen, Genzyme/SanofiGenzyme, Global Blood Therapeutics, Merck Serono, MS Academy, Novartis, Oxford Pharmagenesis, Roche, Tigercat and Vanita. Dawn Langdon has received grants from Merck and Novartis, and has received consulting/advisor fees from Merck, Teva, Bayer, Novartis, Biogen and Almirall. Darin T Okuda reports personal fees from Alexion, Biogen, Celgene, EMD Serono, Genentech, Genzyme and TG Therapeutics, and grants from Biogen, EMD Serono and Genentech, outside the submitted work. Jacqueline Palace reports grants from Merck Serono, Chugai, MedImmun, Alexion and Abide, and personal fees from Merck Serono, Teva, Chugai, MedImmun, Alexion, Novartis, Roche, Abide, Medday, Argenx, Mitsubishi, UCB and Viela Bio, outside the submitted work. In addition, Dr. Palace has a patent (issued through Isis Pharmaceuticals; Diagnosing Multiple Sclerosis) that is not related to present work. Regina María Papais-Alvarenga reports financial support for participation in neurology meetings/congresses, conferences and medical boards from Teva, Merck, Genzyme, Bayer Schering, Novartis, Biogen Idec and participation in clinical trials sponsored by Novartis, Biogen Idec and Roche. Ines Pinto reports personal grant from the European Commission, Marie Curie COFUND Programme. Claudia Chien, Gulfaraz Khan, Najib Kissani, Maria Isabel Leite and Fu-Dong Shi report no conflicts of interest.

Data Availability. Data sharing is not applicable to this article as no datasets were generated or analysed during the current study.

Open Access. This article is licensed under a Creative Commons Attribution-NonCommercial 4.0 International License, which permits any non-commercial use, sharing, adaptation, distribution and reproduction in any medium or format, as long as you give appropriate credit to the original author(s) and the source, provide a link to the Creative Commons licence, and indicate if changes were made. The images or other third party material in this article are included in the article's Creative Commons licence, unless indicated otherwise in a credit line to the material. If material is not included 
in the article's Creative Commons licence and your intended use is not permitted by statutory regulation or exceeds the permitted use, you will need to obtain permission directly from the copyright holder. To view a copy of this licence, visit http://creativecommons.org/licenses/bync/4.0/.

\section{REFERENCES}

1. Thompson AJ, Baranzini SE, Geurts J, et al. Multiple sclerosis. Lancet. 2018;6736:1-15. https://doi.org/ 10.1016/S0140-6736(18)30481-1.

2. Thompson AJ, Banwell BL, Barkhof F, et al. Diagnosis of multiple sclerosis: 2017 revisions of the McDonald criteria. Lancet Neurol. 2018;17:162-73. https://doi.org/10.1016/S1474-4422(17)30470-2.

3. Dutta R, Trapp BD. Relapsing and progressive forms of multiple sclerosis: insights from pathology. Curr Opin Neurol. 2014;27:271-8. https://doi.org/10. 1097/WCO.0000000000000094.

4. Luchetti S, Fransen NL, van Eden CG, et al. Progressive multiple sclerosis patients show substantial lesion activity that correlates with clinical disease severity and sex: a retrospective autopsy cohort analysis. Acta Neuropathol. 2018;135:511-28. https://doi.org/10.1007/s00401-018-1818-y.

5. Frischer JM, Weigand SD, Guo Y, et al. Clinical and pathological insights into the dynamic nature of the white matter multiple sclerosis plaque. Ann Neurol. 2015;78:710-21. https://doi.org/10.1002/ ana. 24497.

6. Lassmann H, van Horssen J, Mahad D. Progressive multiple sclerosis: pathology and pathogenesis. Nat Rev Neurol. 2012;8:647-56. https://doi.org/10. 1038/nrneurol.2012.168.

7. Kutzelnigg A, Lucchinetti CF, Stadelmann C, et al. Cortical demyelination and diffuse white matter injury in multiple sclerosis. Brain. 2005;128: 2705-12. https://doi.org/10.1093/brain/awh641.

8. Lublin FD. New multiple sclerosis phenotypic classification. Eur Neurol. 2014;72(Suppl 1):1-5. https://doi.org/10.1159/000367614.

9. Khalil M, Teunissen CE, Otto M, et al. Neurofilaments as biomarkers in neurological disorders. Nat Rev Neurol. 2018;14:577-89. https://doi.org/10. 1038/s41582-018-0058-z.
10. Robak T, Robak E. New anti-CD20 monoclonal antibodies for the treatment of B-cell lymphoid malignancies. BioDrugs. 2011;25:13-25. https://doi. org/10.2165/11539590-000000000-00000.

11. Gergely P, Nuesslein-Hildesheim B, Guerini D, et al. The selective sphingosine 1-phosphate receptor modulator BAF312 redirects lymphocyte distribution and has species-specific effects on heart rate. $\mathrm{Br}$ J Pharmacol. 2012;167:1035-47. https://doi.org/10. 1111/j.1476-5381.2012.02061.x.

12. Multiple Sclerosis International Federation. Atlas of multiple sclerosis 2013-mapping multiple sclerosis around the world. 2013. https://www.msif.org/wpcontent/uploads/2014/09/Atlas-of-MS.pdf. Accessed 15 May 2019.

13. Börü ÜT, Duman A, Kulualp AS, et al. Multiple sclerosis prevalence study. Medicine (Baltimore). 2018;97:e12856.

14. Akdemir N, Terzi M, Arslan N, et al. Prevalence of multiple sclerosis in the middle black sea region of Turkey and demographic characteristics of patients. Arch Neuropsychiatry. 2017;54:11-4. https://doi. org/10.5152/npa.2016.12451.

15. Börü ÜT, Taşdemir M, Güler N, et al. Prevalence of multiple sclerosis: door-to-door survey in three rural areas of coastal black sea regions of Turkey. Neuroepidemiology. 2011;37:231-5. https://doi.org/10. 1159/000334316.

16. Börü ÜT, Alp R, Sur H, et al. Prevalence of multiple sclerosis door-to-door survey in Maltepe, Istanbul, Turkey. Neuroepidemiology. 2006;27:17-211. https://doi.org/10.1159/000093895.

17. Ait Ben Haddou E, Alhyan M, Aasfara J, et al. Multiple sclerosis: clinical characteristics and disability progression in Moroccan children. J Neurol Sci. 2014;346:128-32. https://doi.org/10.1016/j.jns. 2014.08.008

18. Araqi-Houssaini A, Lahlou I, Benkadmir Y, et al. Multiple sclerosis severity score in a cohort of Moroccan patients. Mult Scler. 2014;20:764-5. https://doi.org/10.1177/1352458513506504.

19. Sidhom Y, Maillart E, du Montcel ST, et al. Fast multiple sclerosis progression in North Africansboth genetics and environment matter. Neurology. 2017;88:1218-25.

20. Bennett J, de Seze J, Lana-Peixoto M, et al. Neuromyelitis optica and multiple sclerosis: seeing differences through optical coherence tomography. Mult Scler J. 2015;21:678-88. https://doi.org/10. $1177 / 1352458514567216$. 
21. Yang C-S, Yang L, Li T, et al. Responsiveness to reduced dosage of rituximab in Chinese patients with neuromyelitis optica. Neurology. 2013;81: 710-3.

22. Zhang C, Tian D, Yang C, et al. Safety and efficacy of bortezomib in patients with highly relapsing neuromyelitis optica spectrum disorder. JAMA Neurol. 2017;74:1010-2.

23. Cristiano E, Romano M, Frider N, et al. The epidemiology of multiple sclerosis in Latin America and the Caribbean: a systematic review. Mult Scler J. 2013;19:844-54. 1352458512462918 . https://doi.org/10.1177/

24. Beatriz A, Nogueira C, Clinete M, et al. Prevalence of multiple sclerosis in Brazil: a systematic review. Mult Scler Relat Disord. 2015;4:572-9. https://doi. org/10.1016/j.msard.2015.08.004.

25. Rosati G. The prevalence of multiple sclerosis in the world: an update. Neurol Sci. 2001;22:117-39.

26. Correale J, Gaitán MI. Multiple sclerosis and environmental factors: the role of vitamin $\mathrm{D}$, parasites, and Epstein-Barr virus infection. Acta Neurol Scand. 2015;132:46-55. https://doi.org/10.1111/ ane.12431.

27. Papais-Alvarenga RM, Vasconcelos CCF, Carra A, et al. Central nervous system idiopathic inflammatory demyelinating disorders in South Americans: a descriptive, multicenter, cross-sectional study. PLoS ONE. 2015;10:e0127757. https://doi.org/10.1371/ journal.pone.0127757.

28. Hillert J, Stawiarz L. The Swedish MS registryclinical support tool and scientific resource. Acta Neurol Scand. 2015;132:11-9. https://doi.org/10. 1111/ane.12425.

29. Manouchehrinia A, Beiki O, Hillert J. Clinical course of multiple sclerosis: a nationwide cohort study. Mult Scler. 2017;23:1488-95. https://doi.org/ $10.1177 / 1352458516681197$.

30. Gyllensten $\mathrm{H}$, Wiberg $\mathrm{M}$, Alexanderson $\mathrm{K}$, et al. Comparing costs of illness of multiple sclerosis in three different years: a population-based study. Mult Scler J. 2018;24:520-8. https://doi.org/10. $1177 /$ https.

31. Westerlind H, Stawiarz L, Fink K, et al. A significant decrease in diagnosis of primary progressive multiple sclerosis: a cohort study. Mult Scler J. 2016;22: 1071-9. https://doi.org/10.1177/ 1352458516643394.

32. Manouchehrinia A, Zhu F, Piani-meier D, et al. Predicting risk of secondary progression in multiple sclerosis: a nomogram. Mult Scler J. 2018. https:// doi.org/10.1177/1352458518783667.

33. Gyllensten H, Kavaliunas A, Alexanderson K, et al. Costs and quality of life by disability among people with multiple sclerosis: a register-based study in Sweden. Mult Scler J Exp Transl Clin. 2018. https:// doi.org/10.1177/2055217318783352.

34. Tedeholm H, Lycke J, Skoog B, et al. Time to secondary progression in patients with multiple sclerosis who were treated with first generation immunomodulating drugs. Mult Scler J. 2012;19: 765-74. 1352458512463764 . https://doi.org/10.1177/

35. Kavaliunas A, Manouchehrinia A, Stawiarz L, et al. Importance of early treatment initiation in the clinical course of multiple sclerosis. Mult Scler J. 2017;23:1233-40. 1352458516675039 .

36. Landfeldt E, Castelo A, Axel B, et al. The long-term impact of early treatment of multiple sclerosis on the risk of disability pension. J Neurol. 2018;265: 701-7. https://doi.org/10.1007/s00415-018-8764-4.

37. Ramanujam R, Hedström A-K, Manouchehrinia A, et al. Effect of smoking cessation on multiple sclerosis prognosis. JAMA Neurol. 2015;72:1117-23. https://doi.org/10.1001/jamaneurol.2015.1788.

38. Brownlee WJ, Hardy TA, Fazekas F, et al. Diagnosis of multiple sclerosis: progress and challenges. Lancet. 2017;389:1336-46. https://doi.org/10.1016/ S0140-6736(16)30959-X.

39. Corsellis JA, Goldberg GJ, Norton AR. 'Limbic encephalitis' and its association with carcinoma. Brain. 1968;91:481-96.

40. Dalmau J, Graus F. Antibody-mediated encephalitis. N Engl J Med. 2018;378:840-51. https://doi.org/10. 1056/NEJMra1708712.

41. Graus F, Titulaer MJ, Balu R, et al. A clinical approach to diagnosis of autoimmune encephalitis. Lancet Neurol. 2016;15:391-404. https://doi.org/ 10.1016/S1474-4422(15)00401-9.

42. Armangue T, Spatola M, Vlagea A, et al. Frequency, symptoms, risk factors, and outcomes of autoimmune encephalitis after herpes simplex encephalitis: a prospective observational study and retrospective analysis. Lancet Neurol. 2018;17: 760-72. https://doi.org/10.1016/S14744422(18)30244-8.

43. Ariño H, Armangué T, Petit-Pedrol M, et al. AntiLGI1-associated cognitive impairment Presentation and long-term outcome. Neurology. 2016;87: 759-65. 
44. Titulaer MJ, McCracken L, Gabilondo II, et al. Treatment and prognostic factors for long-term outcome in patients with anti-NMDA receptor encephalitis: an observational cohort study. Lancet Neurol. 2013;12:157-65. https://doi.org/10.1016/ S1474-4422(12)70310-1.

45. Jurynczyk M, Messina S, Woodhall MR, et al. Clinical presentation and prognosis in MOG-antibody disease: a UK study. Brain. 2017;140:3128-38. https://doi.org/10.1093/brain/awx276.

46. Cobo-Calvo A, Ruiz A, Maillart E, et al. Clinical spectrum and prognostic value of CNS MOG autoimmunity in adults-the MOGADOR study. Neurology. 2018;90:e1858-e18691869. https://doi. org/10.1212/WNL.0000000000005560.

47. Matthews L, Marasco R, Jenkinson $M$, et al. Distinction of seropositive NMO spectrum disorder and MS brain lesion distribution. Neurology. 2013;80:1330-7.

48. Juryńczyk M, Jacob A, Fujihara K, et al. Myelin oligodendrocyte glycoprotein (MOG) antibody-associated disease: practical considerations. Pract Neurol. 2018. https://doi.org/10.1136/practneurol2017-001787.

49. Hacohen Y, Wong YY, Lechner C, et al. Disease course and treatment responses in children with relapsing myelin oligodendrocyte glycoprotein antibody-associated disease. JAMA Neurol. 2018;75: 478-87. https://doi.org/10.1001/jamaneurol.2017. 4601.

50. Ramanathan S, Mohammad S, Tantsis E, et al. Clinical course, therapeutic responses and outcomes in relapsing MOG antibody-associated demyelination. J Neurol Neurosurg psychiatry. 2018;89:127-37. https://doi.org/10.1136/jnnp2017-316880.

51. Giovannoni G, Butzkueven H, Dhib-Jalbut S et al. Brain health-time matters in multiple sclerosis. 2015. https://www.msbrainhealth.org/perch/ resources/brain-health-time-matters-in-multiplesclerosis-sep-17-2.pdf. Accessed 15 May 2019.

52. Hobart J, Bowen A, Pepper G, et al. International consensus on quality standards for brain healthfocused care in multiple sclerosis. Mult Scler. 2018. https://doi.org/10.1177/1352458518809326.

53. Langdon DW. Cognition in multiple sclerosis. Curr Opin Neurol. 2011;24:244-9. https://doi.org/10. 1097/WCO.0b013e328346a43b.

54. Sokolov AA, Grivaz P, Bove R. Cognitive deficits in multiple sclerosis: recent advances in treatment and neurorehabilitation. Curr Treat Options Neurol.
2018;20:53. https://doi.org/10.1007/s11940-0180538-X.

55. Kobelt G, Langdon D, Jonsson L. The effect of selfassessed fatigue and subjective cognitive impairment on work capacity: the case of multiple sclerosis. Mult Scler. 2019; 25(5):740-9. https://doi.org/ $10.1177 / 1352458518769837$.

56. Kavaliunas A, Danylaite Karrenbauer V, Gyllensten $\mathrm{H}$, et al. Cognitive function is a major determinant of income among multiple sclerosis patients in Sweden acting independently from physical disability. Mult Scler. 2019;25:104-12. https://doi.org/ $10.1177 / 1352458517740212$.

57. Zipoli V, Goretti B, Hakiki B, et al. Cognitive impairment predicts conversion to multiple sclerosis in clinically isolated syndromes. Mult Scler. 2010;16:62-7. 1352458509350311 .

https://doi.org/10.1177/

58. Deloire M, Ruet A, Hamel D, et al. Early cognitive impairment in multiple sclerosis predicts disability outcome several years later. Mult Scler. 2010;16: 581-7. https://doi.org/10.1177/1352458510362819.

59. Moccia M, Lanzillo R, Palladino R, et al. Cognitive impairment at diagnosis predicts 10 -year multiple sclerosis progression. Mult Scler. 2016;22:659-67. https://doi.org/10.1177/1352458515599075.

60. Bruce JM, Hancock LM, Arnett P, et al. Treatment adherence in multiple sclerosis: association with emotional status, personality, and cognition. J Behav Med. 2010;33:219-27. https://doi.org/10.1007/ s10865-010-9247-y.

61. Muhlert N, Sethi V, Cipolotti L, et al. The grey matter correlates of impaired decision-making in multiple sclerosis. J Neurol Neurosurg Psychiatry. 2015;86:530-6. https://doi.org/10.1136/jnnp-2014308169 .

62. Radomski AD, Power C, Purdon SE, et al. Decisionmaking under explicit risk is impaired in multiple sclerosis: relationships with ventricular width and disease disability. BMC Neurol. 2015;15:61. https:// doi.org/10.1186/s12883-015-0318-0.

63. Vahter L, Zopp I, Kreegipuu M, et al. Clean intermittent self-catheterization in persons with multiple sclerosis: the influence of cognitive dysfunction. Mult Scler. 2009;15:379-84. https://doi.org/10. $1177 / 1352458508098599$.

64. Kalron A. The relationship between specific cognitive domains, fear of falling, and falls in people with multiple sclerosis. Biomed Res Int. 2014;2014: 281760. https://doi.org/10.1155/2014/281760. 
65. van Vliet R, Hoang P, Lord S, et al. Multiple sclerosis severity and concern about falling: physical, cognitive and psychological mediating factors. NeuroRehabilitation. 2015;37:139-47. https://doi.org/ 10.3233/NRE-151246.

66. Khalil H, Al-Shorman A, El-Salem K, et al. Fear of falling in people with multiple sclerosis: which clinical characteristics are important? Phys Ther. 2017;97:698-706. https://doi.org/10.1093/ptj/ pzx044.

67. D'Orio VL, Foley FW, Armentano F, et al. Cognitive and motor functioning in patients with multiple sclerosis: neuropsychological predictors of walking speed and falls. J Neurol Sci. 2012;316:42-6. https:// doi.org/10.1016/j.jns.2012.02.003.

68. Sosnoff JJ, Balantrapu S, Pilutti LA, et al. Cognitive processing speed is related to fall frequency in older adults with multiple sclerosis. Arch Phys Med Rehabil. 2013;94:1567-72. https://doi.org/10.1016/ j.apmr.2013.02.009.

69. Gunn HJ, Newell P, Haas B, et al. Identification of risk factors for falls in multiple sclerosis: a systematic review and meta-analysis. Phys Ther. 2013;93: 504-13. https://doi.org/10.2522/ptj.20120231.

70. Wajda DA, Moon Y, Motl RW, et al. Preliminary investigation of gait initiation and falls in multiple sclerosis. Arch Phys Med Rehabil. 2015;96: 1098-102. https://doi.org/10.1016/j.apmr.2014.12. 011.

71. Etemadi Y. Dual task cost of cognition is related to fall risk in patients with multiple sclerosis: a prospective study. Clin Rehabil. 2017;31:278-84. https://doi.org/10.1177/0269215516637201.

72. Schultheis MT, Weisser V, Ang J, et al. Examining the relationship between cognition and driving performance in multiple sclerosis. Arch Phys Med Rehabil. 2010;91:465-73. https://doi.org/10.1016/j. apmr.2009.09.026.

73. Marcotte TD, Rosenthal TJ, Roberts E, et al. The contribution of cognition and spasticity to driving performance in multiple sclerosis. Arch Phys Med Rehabil. 2008;89:1753-8. https://doi.org/10.1016/j. apmr.2007.12.049.

74. Badenes D, Garolera M, Casas L, et al. Driving competences and neuropsychological factors associated to driving counseling in multiple sclerosis. J Int Neuropsychol Soc. 2014;20:555-65. https:// doi.org/10.1017/S1355617714000368.

75. Lamargue-Hamel D, Deloire M, Saubusse A, et al. Cognitive evaluation by tasks in a virtual reality environment in multiple sclerosis. J Neurol Sci.
2015;359:94-9. https://doi.org/10.1016/j.jns.2015. 10.039 .

76. Benedict RH, Drake AS, Irwin LN, et al. Benchmarks of meaningful impairment on the MSFC and BICAMS. Mult Scler. 2016;22:1874-82. https://doi. org/10.1177/1352458516633517.

77. Hanna J, Feinstein A, Morrow SA. The association of pathological laughing and crying and cognitive impairment in multiple sclerosis. J Neurol Sci. 2016;361:200-3. https://doi.org/10.1016/j.jns.2016. 01.002 .

78. Morrow SA, Rosehart H, Pantazopoulos K, et al. Anxiety and depressive symptoms are associated with worse performance on objective cognitive tests in MS. J Neuropsychiatry Clin Neurosci. 2016;28: 118-23. https://doi.org/10.1176/appi.neuropsych. 15070167.

79. Goverover Y, Haas S, DeLuca J. Money management activities in persons with multiple sclerosis. Arch Phys Med Rehabil. 2016;97:1901-7. https://doi.org/ 10.1016/j.apmr.2016.05.003.

80. Gerstenecker A, Myers T, Lowry K, et al. Financial capacity and its cognitive predictors in progressive multiple sclerosis. Arch Clin Neuropsychol. 2017;32:943-50. https://doi.org/10.1093/arclin/ acx039.

81. Shevil EBA, Johansson S, Ytterberg C, et al. How are cognitive impairment, fatigue and signs of depression related to participation in daily life among persons with multiple sclerosis? Disabil Rehabil. 2014;36:2012-8. https://doi.org/10.3109/09638288. 2014.887797.

82. Vanner EA, Block P, Christodoulou CC, et al. Pilot study exploring quality of life and barriers to leisure-time physical activity in persons with moderate to severe multiple sclerosis. Disabil Health J. 2008;1:58-655. https://doi.org/10.1016/j.dhjo. 2007.11.001.

83. Cattaneo D, Lamers I, Bertoni R, et al. Participation restriction in people with multiple sclerosis: prevalence and correlations with cognitive, walking, balance, and upper limb impairments. Arch Phys Med Rehabil. 2017;98:1308-15. https://doi.org/10. 1016/j.apmr.2017.02.015.

84. Hughes AJ, Hartoonian N, Parmenter B, et al. Cognitive impairment and community integration outcomes in individuals living with multiple sclerosis. Arch Phys Med Rehabil. 2015;96:1973-9. https://doi.org/10.1016/j.apmr.2015.07.003.

85. Goverover Y, Strober L, Chiaravalloti N, et al. Factors that moderate activity limitation and participation restriction in people with multiple sclerosis. 
Am J Occup Ther. 2015. https://doi.org/10.5014/ ajot.2015.014332.

86. Chalah MA, Ayache SS. Deficits in social cognition: an unveiled signature of multiple sclerosis. J Int Neuropsychol Soc. 2017;23:266-86. https://doi.org/ $10.1017 / \mathrm{S} 1355617716001156$.

87. Dulau C, Deloire M, Diaz H, et al. Social cognition according to cognitive impairment in different clinical phenotypes of multiple sclerosis. J Neurol. 2017;264:740-8. https://doi.org/10.1007/s00415017-8417-z.

88. Labiano-Fontcuberta A, Mitchell AJ, Moreno-Garcia $S$, et al. Cognitive impairment in patients with multiple sclerosis predicts worse caregiver's healthrelated quality of life. Mult Scler. 2014;20:1769-79. https://doi.org/10.1177/1352458514532398.

89. Labiano-Fontcuberta A, Mitchell AJ, Moreno-Garcia $\mathrm{S}$, et al. Anxiety and depressive symptoms in caregivers of multiple sclerosis patients: the role of information processing speed impairment. J Neurol Sci. 2015;349:220-5. https://doi.org/10.1016/j.jns. 2015.01.024.

90. Benedict RHB, Munschauer F, Linn R, et al. Screening for multiple sclerosis cognitive impairment using a self-administered 15-item questionnaire. Mult Scler. 2003;9:95-101. https://doi.org/10. 1191/1352458503ms861oa.

91. Akbar N, Honarmand K, Feinstein A. Self-assessment of cognition in multiple sclerosis: the role of personality and anxiety. Cogn Behav Neurol. 2011;24:115-21. https://doi.org/10.1097/WNN. 0b013e31822a20ae.

92. Beier M, Amtmann D, Ehde DM. Beyond depression: Predictors of self-reported cognitive function in adults living with MS. Rehabil Psychol. 2015;60: 254-62. https://doi.org/10.1037/rep0000045.

93. Hughes AJ, Beier M, Hartoonian N, et al. Self-efficacy as a longitudinal predictor of perceived cognitive impairment in individuals with multiple sclerosis. Arch Phys Med Rehabil. 2015;96:913-9. https://doi.org/10.1016/j.apmr.2015.01.008.

94. Langdon DW, Amato MP, Boringa J, et al. Recommendations for a brief international cognitive assessment for multiple sclerosis (BICAMS). Mult Scler. 2012;18:891-8. https://doi.org/10.1177/ 1352458511431076.

95. Kim S-H, Mealy MA, Levy M, et al. Racial differences in neuromyelitis optica spectrum disorder. Neurology. 2018;91:e2089-e20992099. https://doi.org/10. 1212/WNL.0000000000006574.
96. Bourre B, Marignier R, Zéphir H, et al. Neuromyelitis optica and pregnancy. Neurology. 2012;78:875-9. https://doi.org/10.1212/WNL.0b013e31824c466f.

97. Vukusic S, Hutchinson M, Hours M, et al. Pregnancy and multiple sclerosis (the PRIMS study): clinical predictors of post-partum relapse. Brain. 2004;127: 1353-60. https://doi.org/10.1093/brain/awh152.

98. Kim W, Kim S-H, Nakashima I, et al. Influence of pregnancy on neuromyelitis optica spectrum disorder. Neurology. 2012;78:1264-7. https://doi.org/ 10.1212/WNL.0b013e318250d812.

99. Shimizu Y, Fujihara K, Ohashi T, et al. Pregnancyrelated relapse risk factors in women with antiAQP4 antibody positivity and neuromyelitis optica spectrum disorder. Mult Scler. 2016;22:1413-20. https://doi.org/10.1177/1352458515583376.

100. Nour MM, Coutinho E, George J, et al. Pregnancy outcomes in aquaporin-4-positive neuromyelitis optica spectrum disorder. Neurology. 2016;86: 79-877. https://doi.org/10.1212/WNL. 0000000000002208 .

101. Houtchens MK, Edwards NC, Schneider G, et al. Pregnancy rates and outcomes in women with and without MS in the United States. Neurology. 2018;91:e1559-e15691569. https://doi.org/10. 1212/WNL.0000000000006384.

102. Confavreux C, Hutchinson M, Hours MM, et al. Rate of pregnancy-related relapse in multiple sclerosis. N Engl J Med. 1998;339:285-91. https://doi. org/10.1056/NEJM199807303390501.

103. Bsteh G, Algrang L, Hegen H, et al. Pregnancy and multiple sclerosis in the DMT era: a cohort study in Western Austria. Mult Scler. 2018. https://doi.org/ $10.1177 / 1352458518816614$.

104. Nguyen A-L, Havrdova EK, Horakova D, et al. Incidence of pregnancy and disease-modifying therapy exposure trends in women with multiple sclerosis: a contemporary cohort study. Mult Scler Relat Disord. 2019;28:235-43. https://doi.org/10.1016/j.msard. 2019.01.003.

105. Celius EG, Ciplea AI, Drulović J, et al. Alemtuzumab and pregnancy-case series from the German MS and Pregnancy Registry, Norway and Serbia. In: Poster Session 2: Poster P915. Mult Scler J. 2018;24: 328-529. https://doi.org/10.1177/ 1352458518798590 .

106. Langer-Gould A, Smith JB, Hellwig K, et al. Breastfeeding, ovulatory years, and risk of multiple sclerosis. Neurology. 2017;89:563-9. https://doi.org/10. 1212/WNL.0000000000004207. 
107. Voskuhl R, Momtazee C. Pregnancy: effect on multiple sclerosis, treatment considerations, and breastfeeding. Neurotherapeutics. 2017;14:974-84. https://doi.org/10.1007/s13311-017-0562-7.

108. Khan G, Coates PJ, Gupta RK, et al. Presence of Epstein-Barr virus in Hodgkin's disease is not exclusive to Reed-Sternberg cells. Am J Pathol. 1992;140:757-62.

109. Khan G, Coates PJ, Kangro HO, et al. Epstein Barr virus (EBV) encoded small RNAs: targets for detection by in situ hybridisation with oligonucleotide probes. J Clin Pathol. 1992;45:616-20.

110. Khan G, Norton AJ, Slavin G. Epstein-Barr virus in Hodgkin disease. Relation to age and subtype. Cancer. 1993;71:3124-9.

111. Cepok S, Zhou D, Srivastava R, et al. Identification of Epstein-Barr virus proteins as putative targets of the immune response in multiple sclerosis. J Clin Invest. 2005;115:1352-60. https://doi.org/10.1172/ JCI23661.

112. Haahr S, Plesner AM, Vestergaard BF, et al. A role of late Epstein-Barr virus infection in multiple sclerosis. Acta Neurol Scand. 2004;109:270-5. https://doi. org/10.1046/j.1600-0404.2003.00221.x.

113. Ponsonby A-L, van der Mei I, Dwyer T, et al. Exposure to infant siblings during early life and risk of multiple sclerosis. JAMA. 2005;293:463-9. https:// doi.org/10.1001/jama.293.4.463.

114. Serafini B, Rosicarelli B, Franciotta D, et al. Dysregulated Epstein-Barr virus infection in the multiple sclerosis brain. J Exp Med. 2007;204:2899-912. https://doi.org/10.1084/jem.20071030.

115. Opsahl ML, Kennedy PGE. An attempt to investigate the presence of Epstein Barr virus in multiple sclerosis and normal control brain tissue. J Neurol. 2007;254:425-30. https://doi.org/10.1007/s00415006-0316-7.

116. Willis SN, Stadelmann C, Rodig SJ, et al. Epstein-Barr virus infection is not a characteristic feature of multiple sclerosis brain. Brain. 2009;132:3318-28. https://doi.org/10.1093/brain/awp200.

117. Sargsyan SA, Shearer AJ, Ritchie AM, et al. Absence of Epstein-Barr virus in the brain and CSF of patients with multiple sclerosis. Neurology. 2010;74:1127-35. https://doi.org/10.1212/WNL. 0b013e3181d865a1.

118. Aloisi F, Serafini B, Magliozzi R, et al. Detection of Epstein-Barr virus and B-cell follicles in the multiple sclerosis brain: what you find depends on how and where you look. Brain. 2010;133:e157. https:// doi.org/10.1093/brain/awq223.
119. Hassani A, Corboy JR, Al-Salam S, et al. Epstein-Barr virus is present in the brain of most cases of multiple sclerosis and may engage more than just B cells. PLoS ONE. 2018;13:e0192109. https://doi.org/ 10.1371/journal.pone.0192109.

120. Tzartos JS, Khan G, Vossenkamper A, et al. Association of innate immune activation with latent Epstein-Barr virus in active MS lesions. Neurology. 2012;78:15-23. https://doi.org/10.1212/WNL. Ob013e31823ed057.

121. Khan G, Ahmed W, Philip PS, et al. Healthy rabbits are susceptible to Epstein-Barr virus infection and infected cells proliferate in immunosuppressed animals. Virol J. 2015;12:28. https://doi.org/10. 1186/s12985-015-0260-1.

122. Abreu CM, Soares-Dos-Reis R, Melo PN, et al. Emerging biosensing technologies for neuroinflammatory and neurodegenerative disease diagnostics. Front Mol Neurosci. 2018;11:164. https:// doi.org/10.3389/fnmol.2018.00164.

123. Cruz A, Queiros R, Abreu CM, et al. Electrochemical immunosensor for TNFalpha-mediated inflammatory disease screening. ACS Chem Neurosci. 2019;10:2676-82. https://doi.org/10.1021/ acschemneuro.9b00036.

124. Maggi P, Absinta M, Grammatico M, et al. Central vein sign differentiates multiple sclerosis from central nervous system inflammatory vasculopathies. Ann Neurol. 2018;83:283-94. https://doi. org/10.1002/ana.25146.

125. Glasser MF, Van Essen DC, Manuscript A, et al. Mapping human cortical areas in vivo based on myelin content as revealed by T1- and T2-weighted MRI. J Neurosci. 2011;31:11597-616. https://doi. org/10.1523/JNEUROSCI.2180-11.2011.

126. Glasser MF, Coalson TS, Robinson EC, et al. A multimodal parcellation of human cerebral cortex. Nature. 2016;536:171-8. https://doi.org/10.1038/ nature18933.

127. Backner Y, Kuchling J, Massarwa S, et al. Anatomical wiring and functional networking changes in the visual system following optic neuritis. JAMA Neurol. 2018;75:287-95. https://doi.org/10.1001/ jamaneurol.2017.3880.

128. Finke C, Zimmermann H, Pache F, et al. Association of visual impairment in neuromyelitis optica spectrum disorder with visual network reorganization visual network reorganization in neuromyelitis optica spectrum disorder visual network reorganization in neuromyelitis optica spectrum disorder. JAMA Neurol. 2018;75:296-303. https://doi.org/10. 1001/jamaneurol.2017.3890. 
129. Ciccarelli O, Cohen JA, Reingold SC, et al. Spinal cord involvement in multiple sclerosis and neuromyelitis optica spectrum disorders. Lancet Neurol. 2019;18:185-97. https://doi.org/10.1016/ S1474-4422(18)30460-5.

130. Gros C, De Leener B, Badji A, et al. Automatic segmentation of the spinal cord and intramedullary multiple sclerosis lesions with convolutional neural networks. Neuroimage. 2019;184:901-15. https:// doi.org/10.1016/j.neuroimage.2018.09.081.

131. Petzold A, Balcer LJ, Calabresi PA, et al. Retinal layer segmentation in multiple sclerosis: a systematic review and meta-analysis. Lancet Neurol. 2017;16: 797-812. https://doi.org/10.1016/S14744422(17)30278-8.

132. Zimmermann HG, Knier B, Oberwahrenbrock $\mathrm{T}$, et al. Association of retinal ganglion cell layer thickness with future disease activity in patients with clinically isolated syndrome. JAMA Neurol. 2018;75:1071-9. jamaneurol.2018.1011.

133. Oertel FC, Havla J, Roca-Fernandez A, et al. Retinal ganglion cell loss in neuromyelitis optica: a longitudinal study. J Neurol Neurosurg Psychiatry. 2018;89:1259-65. https://doi.org/10.1136/jnnp2018-318382.

134. Xu SC, Kardon RH, Leavitt JA, et al. Optical coherence tomography is highly sensitive in detecting prior optic neuritis. Neurology. 2019;92: e527-e535535. https://doi.org/10.1212/WNL. 0000000000006873 .

135. Kantarci OH, Lebrun C, Siva A, et al. Primary progressive multiple sclerosis evolving from radiologically isolated syndrome. Ann Neurol. 2016;79: 288-94. https://doi.org/10.1002/ana.24564. 